\title{
Arbor
}

\section{Debate en torno a la comercialización de los alimentos transgénicos}

\section{Daniel Ramón y María Dolores Calvo}

Arbor CLXVIII, 661 (Enero 2001), 171-186 pp.

La aplicación de la genética a la alimentación es tan antigua como la agricultura o la ganadería. Desde que el hombre comenzó a cultivar vegetales o domesticar animales viene llevando a cabo un proceso de mejora genética valiéndose sobre todo de la técnica del cruce sexual. Por ello podemos afirmar que ninguno de los alimentos que consumimos en nuestra dieta es, desde el punto de vista genético, igual al que comían nuestros abuelos. Los últimos años han dado lugar a la aplicación de técnicas genéticas novedosas como la ingeniería genética a la tecnología de alimentos. La consecuencia ha sido la aparición de los denominados alimentos transgénicos. La comercialización de estos nuevos alimentos ha generado una gran polémica en los países miembros de la Unión Europea. Sus posibles riesgos sanitarios, medioambientales o económicos son tema constante de debate, en la mayoría de los casos con grandes dosis de apasionamiento y pocas de racionalidad. En este trabajo se pretende llevar a cabo una revisión sobre dicha situación.

\section{Alimentos transgénicos: qué son, cuántos hay y qué tienen de particular}

Un alimento transgénico es aquel en cuyo diseño intervienen técnicas de ingeniería genética ${ }^{1}$. El término «transgénico» sólo se utiliza en 
los países castellanoparlantes, ya que en otros países de nuestro entorno se habla de ellos como «alimentos modificados genéticamente» (genetically modified foods). No es un término científicamente correcto, ya que por transgenia se entiende la expresión del gen de un organismo en otro, y existen alimentos transgénicos donde se modula la expresión de un gen propio por ingeniería genética pero no se expresa gen alguno proveniente de otro organismo. Además, se trata de un término en evolución. Hasta hace unos meses, el consumidor europeo entendía que un alimento transgénico era aquel en el que se modificaba por ingeniería genética la materia prima o, en el caso de los alimentos fermentados, el microorganismo responsable de la fermentación, llamado vulgarmente iniciador. Esta situación ha variado, y ahora el consumidor europeo no sólo entiende por alimento transgénico aquel en el que se modifica por ingeniería genética la materia prima o el iniciador, sino también aquel que porta un aditivo alimentario obtenido a partir de un organismo modificado por ingeniería genética. La consecuencia es clara: si una galleta porta almidón obtenido a partir de un maíz modificado genéticamente esta galleta es transgénica. Esta ampliación de la definición de alimento transgénico es una realidad social que origina consecuencias imprevisibles. Quizás la más llamativa de todas consista en que un porcentaje elevado de los alimentos contiene enzimas añadidos y, según datos recientes, un $50 \%$ de los enzimas alimentarios se obtienen a partir de microorganismos modificados genéticamente ${ }^{2}$, con lo que deberíamos clasificar como alimentos transgénicos muchos de los convencionales actuales.

Estas dos posibles definiciones dificultan el conocimiento de cuantos alimentos transgénicos se comercializan en la actualidad. Si nos atenemos a la definición estricta de alimento transgénico sabemos que no más de sesenta en todo el mundo, la gran mayoría de ellos en Estados Unidos, Australia, Canadá o Japón. Si evaluamos no sólo los que se comercializan, sino aquellos que están en última fase de experimentación o en solicitud de permiso de comercialización, podemos calcular un número superior a trescientos. Ahora bien, si asumimos la definición amplia, es imposible contestar a esta pregunta ya que existen miles de alimentos que contienen enzimas, lecitinas, almidones o harinas provenientes de organismos modificados genéticamente.

¿Qué diferencian los alimentos transgénicos de los convencionales? En principio sólo la técnica genética utilizada en su diseño. Como anteriormente se indicó, venimos aplicando genética a la alimentación desde el comienzo de la agricultura y la ganadería. En cualquier alimento convencional ha habido un proceso de mejora genética por cruce 
Debate en torno a la comercialización de los...

sexual y, en menos casos por mutagénesis. En el alimento transgénico, esa mejora se ha obtenido por ingeniería genética. Las consecuencias son las siguientes:

i) En el diseño de un alimento transgénico prima la direccionalidad frente al azar. En el cruce sexual se juntan dos genomas al azar con varios miles de genes cada uno de ellos hasta obtener la combinación adecuada. Mediante ingeniería genética se toma el gen adecuado y en un único paso se introduce en el genoma receptor logrando la combinación deseada.

ii) En el diseño de un alimento transgénico es posible obtener la combinación genética adecuada de forma mucho más rápida. No hay una estrategia de tiro y error.

iii) Es posible saltar la barrera de especie. Todos los organismos vivos tiene $\mathrm{ADN}$ como material hereditario. Por ello es posible transferir genes de un organismo a otro. No es posible cruzar sexualmente una fresa con una patata, pero se pueden expresar genes de fresa en patatas o viceversa.

Es evidente que se trata de diferencias técnicas pero la última de ellas tiene claras repercusiones éticas. Por ejemplo, un hipotético vegetal transgénico que porte un gen de un animal puede ser un problema para un vegetariano de dieta estricta. Es, bajo nuestro punto de vista, muy importante que los científicos que trabajan en estos temas tengan presentes estas consecuencias en sus investigaciones.

\section{Tipos de alimentos transgénicos}

Con frecuencia el consumidor europeo piensa que no hay mas alimentos transgénicos que la soja y el maíz transgénicos Como anteriormente se comentó, ateniéndose a la definición estricta existen más de trescientos alimentos transgénicos en últimas fases de experimentación o primeras de solicitud de comercialización. Pueden ser de origen animal, vegetal o fermentado y, aunque en la mayoría de las ocasiones han sido desarrollados por compañías multinacionales del sector, los hay diseñados en organismos públicos de investigación. Veamos algunos ejemplos.

Se han diseñado una gran variedad de vegetales transgénicos comestibles. Sobre todo se han construido plantas resistentes al ataque por plagas, así como vegetales con mayor vida útil o mejorados en cuanto a su composición nutricional o propiedades organolépticas. El 
ejemplo más conocido es el del maíz transgénico que resiste el ataque del taladro (un gusano que produce enormes pérdidas anuales) al contener un gen de la bacteria Bacillus thuringiensis que da lugar a la síntesis de la proteína tóxica $B t^{3}$. El empleo de este vegetal transgénico constituye un ejemplo de beneficio tanto para el productor que vende sus semillas transgénicas como para el agricultor que ve protegida sus plantaciones. Por el contrario no oferta algo nuevo al consumidor, ya que las propiedades organolépticas y nutricionales de este maíz transgénico son las mismas que las de un maíz convencional. Un ejemplo distinto es el del tomate FlavrSavr ${ }^{\mathrm{TM}}$, el primer alimento transgénico que obtuvo el permiso de comercialización en todo el mundo ${ }^{4}$. Este tomate tiene limitada la capacidad de producir poligalacturonasa, un enzima que degrada la pectina produciendo el ablandamiento del fruto. Como consecuencia el tomate retrasa su ablandamiento y puede almacenarse durante largos períodos sin que se produzcan cambios de color o sabor. Un claro beneficio para el consumidor, pero también para las grandes superficies que pueden almacenar durante más semanas el producto sin pérdida de vida comercial. Un último caso de vegetal transgénico en el que el beneficiado es sólo el consumidor hace referencia al reciente desarrollo de una variedad de patata transgénica que, al contener el gen de la subunidad B de la toxina del cólera, es capaz de inmunizar contra esta enfermedad ${ }^{5}$. La vacuna es el propio vegetal, evitando así los problemas de pérdida de la cadena de frío asociados a la vacunación, sobre todo en países del Tercer Mundo. No es el único caso, existen más vegetales transgénicos que actúan como vacunas orales, e incluso algunos de ellos han sido ensayados con éxito en humanos ${ }^{6}$.

En alimentos transgénicos animales se ha avanzado menos, aunque es posible construir animales de granja transgénicos. Se ha investigado la producción de animales de mayor tamaño y la utilización de la glándula mamaria de vacas, cerdos u ovejas como una factoría celular. Se han construido carpas y salmones transgénicos que portan múltiples copias del gen de la hormona de crecimiento de la trucha y ganan tamaño mucho más rápido con el consiguiente beneficio para el productor ${ }^{7}$. Ahora bien, sin duda las mejores perspectivas de futuro la tienen la expresión de genes que codifican proteínas de alto valor añadido en la glándula mamaria de diferentes mamíferos ${ }^{8}$. Como consecuencia se produce una leche enriquecida en determinados productos como el activador del plasminógeno o el factor antihemofílico, con lo que un rebaño de tamaño medio podría producir la suficiente cantidad de estos fármacos para poder atender la demanda de todos los enfermos 
Debate en torno a la comercialización de los...

actuales durante un año. Muy recientemente se ha descrito la construcción de un mamífero transgénico que expresa en su leche una enzima que degrada la lactosa ${ }^{9}$. La leche producida es ideal para el consumo por parte de enfermos intolerantes a la lactosa. Todos estos casos son beneficios importantes para el consumidor.

Finalmente, también en el caso de los alimentos fermentados se han aplicado técnicas de ingeniería genética. Se han construido bacterias lácticas o levaduras transgénicas que portan genes de otros organismos. Los resultados son quesos en los que es posible controlar, e incluso acortar, los tiempos de maduración sin pérdida de calidad ${ }^{10}$, o vinos con un incremento de aroma afrutado, una característica organoléptica muy apreciada por el consumidor centroeuropeo ${ }^{11}$. De todo lo expuesto resulta evidente que nos enfrentamos a una nueva tecnología en expansión que puede cambiar la oferta alimentaria de nuestros hijos. En este sentido resulta esclarecedor confirmar que la asociación de compañías biotecnológicas americanas espera obtener en el año 2000 unos beneficios de varios miles de millones de dólares por la venta de estos productos ${ }^{12}$.

\section{¿Son peligrosos los alimentos transgénicos?}

Los logros que se han descrito en las líneas anteriores son importantes. Las nuevas combinaciones de genes en un alimento transgénico permiten desarrollar lo hasta ahora inabordable. Frente a esta postura hay organizaciones que hablan de riesgos ${ }^{13}$. ¿Qué hay de cierto en todo ello?. Para contestar a esta pregunta hay que partir de tres supuestos:

i) Riesgo cero no existe. En alimentación esta afirmación es clara, ya que no hay una uniformidad en las poblaciones y determinados riesgos pueden afectar sólo a determinadas subpoblaciones. Por ejemplo, el gluten de trigo es un peligro para los celíacos pero no para el resto de la población.

ii) No es posible generalizar al hablar de riesgos de los alimentos transgénicos. Se hace preciso recordar una vez más el gran número de alimentos transgénicos desarrollados y la imposibilidad de dar una respuesta global con respecto a su inocuidad. En otras palabras, como en el caso de los fármacos, la evaluación caso por caso, alimento transgénico por alimento transgénico, parece la forma más racional de abordar el estudio. 
iii) No existe un solo riesgo. Pueden darse riesgos sanitarios y medioambientales e incluso económicos. Como consecuencia, para cada alimento transgénico habría que evaluar cada tipo de riesgo.

Organismos internacionales como la FAO, la OMS o la OCDE han establecido durante los últimos años sus propios grupos de trabajo sobre la seguridad para el consumidor de los nuevos alimentos transgénicos, concediéndole prioridad a la elaboración de los principios científicos de evaluación de la misma. La conclusión de estos grupos de trabajo es el desarrollo del concepto de equivalencia sustancial. Este concepto, utilizado por la normativa europea sobre la comercialización de alimentos transgénicos, otorga dicha categoría a aquellos alimentos transgénicos cuya composición nutricional y características organolépticas son iguales a aquel del que proviene, con la única excepción del nuevo carácter introducido por ingeniería genética ${ }^{14}$. En cualquiera de los alimentos transgénicos que se han comercializado hasta la fecha se ha llevado a cabo una evaluación de riesgos sanitarios atendiendo a tres criterios: el contenido nutricional (equivalencia sustancial), la posible presencia de alérgenos y el nivel de toxicidad (para una revisión de casos ver ${ }^{15-16}$ ). La conclusión de todos estos estudios es que no existe un solo dato científico que indique que dichos alimentos, por el hecho de ser transgénicos representen un riesgo para la salud del consumidor superior al que implica la ingestión del alimento convencional correspondiente.

Pese a ello, y como antes indicamos, se habla de riesgos sanitarios ${ }^{13}$. Se hace referencia a aumentos de casos de alergia, peligro de aparición de resistencias a antibióticos, generación de cánceres o retardos en el desarrollo inmunitario. Con respecto al primer problema, la generación de alergias, hay que destacar que sólo en un caso de todos los evaluados hasta la fecha se ha detectado un problema de alergenicidad. Se trata de una soja transgénica que contiene un gen proveniente del genoma de la nuez brasileña y como consecuencia puede resultar perjudicial para consumidores que sean alérgicos a dicho fruto seco ${ }^{17}$. Este problema se detectó durante la evaluación del producto previa a la concesión del permiso de comercialización $y$, aunque este último se obtuvo siempre y cuando se etiquetara el alimento transgénico, la compañía productora decidió no comercializarlo. Con el resto de alimentos transgénicos ensayados hasta la fecha no se han detectado problemas de alergenicidad, es más, existen desarrollos transgénicos que los eliminan. Este es el caso de una levadura panadera transgénica desarrollada en el Consejo Superior de Investigaciones Científicas cuyo uso previene la aparición 
Debate en torno a la comercialización de los...

de alergias inespecíficas en profesionales del sector panadero ligadas a la adición de enzimas durante la panificaciónm ${ }^{18}$.

El uso de genes que codifican resistencia a antibióticos como marcadores de selección en plantas, animales o microorganismos transgénicos abrió la polémica sobre la posible transferencia de dichos genes desde el alimento transgénico a bacterias de la microbiota intestinal y la posible aparición de nuevas cepas bacterianas resistentes a antibióticos. No hay pruebas ni datos experimentales que apoyen esta hipótesis, lo que llevó en su día a la OMS a afirmar que la presencia de genes de resistencia a antibióticos per se en un alimento no debería constituir un riesgo para la salud ${ }^{19}$. Sin embargo, durante los últimos años y por el rechazo social generado en torno a este tema, se han desarrollado técnicas que permiten eliminar los marcadores de resistencia en el producto final obviando el problema ${ }^{20}$. Pese a ello, este argumento se sigue utilizando. Finalmente, a mediados del año 1998 en el Reino Unido se generó una campaña en contra de los alimentos transgénicos tras aparecer el Dr. Arpard Pustzai en un programa de la televisión inglesa afirmando que ratas alimentadas con patatas transgénicas que expresaban lectinas tenían retardos en el desarrollo inmunitario. Dicha campaña se extendió a otros países de la UE, mereciendo en nuestro país primeras páginas y editoriales en varios periódicos de tirada nacional. Conviene aclarar que dichas patatas transgénicas fueron diseñadas en organismos públicos de investigación para disponer de controles positivos de toxicidad. En ningún caso se pretendía comercializarlas. Además, muy recientemente los resultados del Dr. Pustzai han sido publicados en la revista The Lancet, a pesar de haber sido rechazados y criticados por seis recensores ${ }^{21}$. La opinión de los expertos en evaluación toxicológica no puede ser más negativa: los datos son incompletos, se han incluido pocos animales en el experimento $\mathrm{y}$ hay deficiencias en los controles ${ }^{22,}{ }^{23}$. En resumen, un trabajo poco riguroso unido a los deseos de notoriedad de un científico generaron un alarmismo social que fue expandido por la prensa, la misma prensa que meses más tarde apenas ha dado cabida a la noticia sobre la falta de fundamento científico de dichas investigaciones.

$\mathrm{Si}$ analizamos el riesgo que para el medio ambiente supone la aparición de estos alimentos, sobre todo la de los vegetales transgénicos, las cosas son, desde el punto de vista científico, menos claras. El problema fundamental radica en la falta de conocimiento y metodologías para analizar riesgos medioambientales, tanto de las plantas transgénicas como de las convencionales. A menudo se habla de la posible transferencia de los genes exógenos desde la variedad transgénica a 
variedades silvestres. Esta transferencia se produce frecuentemente en la Naturaleza, en algunas especies convencionales más que en otras. Por eso podemos afirmar que, por ejemplo en Europa, la transferencia de genes es improbable si utilizamos maíz transgénico y probable si utilizamos soja transgénica ${ }^{24}$. Conviene recordar que ese mismo riesgo se da con cualquier variedad de maíz resistente generada por cruce sexual: el problema no son los alimentos transgénicos en sí, sino nuestro desconocimiento en materia de evaluación medioambiental. Hasta la fecha se han realizado más de 25000 liberaciones controladas de plantas transgénicas al medio ambiente y se ha detectado un caso de transferencia de genes de una variedad transgénica de colza a una variedad silvestre ${ }^{25}$. ¿Supone esta nueva variedad un riesgo ecológico?. Los grupos que han trabajado en el tema han concluido que no hay indicaciones de ello ${ }^{26}$. Aun así, resulta evidente que hay que analizar caso por caso y que el control sobre este tipo de experimentos debe ser riguroso.

Un segundo riesgo medioambiental lo constituye la pérdida de biodiversidad asociada al cultivo de plantas transgénicas. Desgraciadamente ésta se viene produciendo desde que el hombre decidió hacerse agricultor y somos los consumidores con nuestros gustos los que la alimentamos. A finales del siglo XVIII en Lleida había 24 variedades distintas de manzanas. Hoy sólo se cultivan dos y no son ninguna de aquellas, sino las que el consumidor demanda. Esta problemática tiene, entre otros, un freno racional consistente en potenciar los bancos de germoplasma y las colecciones de cultivo. Finalmente, otro posible riesgo medioambiental hace referencia a los efectos dañinos que ciertas plantas transgénicas resistentes a insectos pueden tener sobre poblaciones de insectos distintas a aquellas contra las que protegen. Hace unos meses todos los medios de comunicación se hicieron eco de un trabajo científico que demostraba que las larvas de la mariposa monarca morían al ingerir polen de maíz transgénico, a pesar de que los propios autores indicaban en su artículo lo prematuro de sus investigaciones ${ }^{27}$. La reacción del mundo académico a la publicación de dicho trabajo fue inmediata, concluyéndose que los datos presentados eran poco convincentes e incompletos, pero como en el caso Pustzai, dichas conclusiones tuvieron poca difusión en los medios de comunicación ${ }^{28}$.

\section{Beneficios de los alimentos transgénicos: ¿un negocio de multinacionales?}

Como en el caso de los riesgos, es imposible generalizar los beneficios que se pueden obtener de los alimentos transgénicos. Conviene destacar 
Debate en torno a la comercialización de los...

que uno que nunca se logrará es el de acabar con el problema del hambre en el mundo, algo defendido en ocasiones por algunas compañías del sector y biotecnólogos entusiastas. Este problema tiene solución hoy en día al producirse la suficiente cantidad de alimentos para que nadie pase hambre, pero por desgracia el reparto de excedentes alimentarios es un problema político sin solución. Para hablar de beneficios merece la pena formularse la pregunta ¿para qué queremos alimentos transgénicos?. La respuesta a esta pregunta difiere en función de donde vivamos. En países desarrollados como el nuestro es evidente que nos preocupa la calidad de nuestra comida. Estamos obsesionados por que aquello que comemos sepa bien y favorezca nuestra salud. Atendiendo a estas demandas, mediante ingeniería genética es posible conseguir desarrollos inabordables por tecnologías convencionales. Ejemplos de ellos son las levaduras transgénicas que incrementan el aroma afrutado de los vinos ${ }^{11}$, las semillas transgénicas que producen aceites con un contenido de ácidos grasos adecuado ${ }^{29}$ o las patatas transgénicas sobreproductoras de almidón que acumulan menos aceite al freirse ${ }^{30}$. ¿Cómo pueden beneficiarse los países del Tercer Mundo? La respuesta es obvia: se pueden construir variedades de papaya capaces de crecer en suelos ácidos ${ }^{31}$, se pueden diseñar alimentos que actúen como vacunas ${ }^{5,6}$ e incluso se pueden conseguir variedades de arroz transgénico con un alto contenido de provitamina A y hierro capaces de solventar los problemas de avitaminosis y carencia de este metal en zonas subdesarrolladas donde este cereal es la base de la $\operatorname{dieta}^{32}$.

Ahora bien, todo ello hay que ponerlo en su contexto. La inmensa mayoría de alimentos transgénicos son producidos por compañías multinacionales interesadas tan sólo en aquellos cultivos que consumen los países desarrollados. En este sentido merece la pena hacer una doble reflexión. Por un lado, indicar que no se han creado compañías nuevas para vender alimentos transgénicos. El centrar el debate de los alimentos transgénicos en una campaña contra las multinacionales es, cuanto menos, una ingenuidad con un cierto grado de perversión. Por otro, recordar a los científicos que trabajan en organismos públicos de investigación su obligación moral de apoyar en la medida de sus posibilidades a los ciudadanos de países desfavorecidos, ya sea formando científicos de dichas nacionalidades en las técnicas de ingeniería genética, ya sea cooperando científicamente con ellos utilizando como material de trabajo sus variedades autóctonas. 


\section{La opinión del consumidor: el problema del etiquetado}

Se estima que sólo en el intervalo comprendido entre los años 1984 y 1994 se ha entrevistado a más de 70.000 personas, sobre todo en Estados Unidos, Japón y Europa, para conocer su opinión sobre la biotecnología ${ }^{33}$. Apenas se dispone de datos en países subdesarrollados. La heterogeneidad de las poblaciones encuestadas, del tipo de encuesta (telefónica, escrita, entrevista personal), o de las preguntas, dificulta el obtener tendencias entre consumidores de distintos países. No obstante es posible extraer ciertas características propias de poblaciones. Así, en Estados Unidos el conocimiento sobre biotecnología es bajo y su aceptación alta. En Europa la situación es contradictoria: en los países del norte de Europa el público tiende a estar informado acerca de esta tecnología y presenta objeciones éticas y morales; por el contrario, en los países del Sur el conocimiento es menor y la aceptación mayor. En cualquier caso, las opiniones varían en función del tiempo. Quedan muy lejos las encuestas en el Reino Unido que denotaban hace apenas dos años una aceptación razonable de los alimentos transgénicos. El escándalo Pustzai dio un vuelco a esta situación que, a pesar de la falta de base, no se ha recuperado.

Se han realizado diversas encuestas para conocer la opinión del consumidor sobre los alimentos transgénicos ${ }^{34,35}$. De ellas se extraen las siguientes generalidades:

i) Hay un desconocimiento profundo sobre qué es biotecnología, ingeniería genética y alimentos transgénicos.

ii) Se observa un rechazo frontal a todo aquello que implique la modificación genética de animales, y más si se manipulan genes provenientes de células humanas.

iii) Las variedades vegetales transgénicas o la producción de levaduras o bacterias lácticas transgénicas que produzcan respectivamente vino, cerveza o yogur son mejor aceptadas por el consumidor, sobre todo si la modificación genética afecta positivamente al producto final. No es tan receptiva la postura si la modificación tan sólo favorece al productor.

iv) Los consumidores están unánimemente a favor del etiquetado de los alimentos transgénicos.

La percepción de riesgos y el interés por el consumo de alimentos transgénicos varía entre distintos países. Recientemente se han llevado a cabo encuestas que demuestran que la mayoría de consumidores en Suecia (65\%), Portugal (62\%), Austria (60\%) y Alemania (57\%) con- 
Debate en torno a la comercialización de los...

sidera la ingeniería genética un riesgo importante, mientras que en Grecia (33\%), Italia (30\%), Noruega (28\%) y Estados Unidos (21\%) sólo opina así una minoría ${ }^{36}$. La actitud positiva hacia el consumo de alimentos transgénicos es muy alta en Canadá (74\%), Estados Unidos (73\%), Portugal (71\%) y Japón (69\%), y muy baja en Alemania (30\%) y Austria (22\%). Curiosamente, a pesar de considerar los alimentos transgénicos un riesgo, los consumidores portugueses aceptan su consumo. De hecho, la percepción de riesgos y el consumo presentan interesantes controversias: la media de consumidores califica a los alimentos transgénicos con un porcentaje de peligrosidad del $44 \%$ frente a un $38 \%$ para el colesterol y un 58\% para el consumo de alimentos pasados de la fecha de caducidad. En otras encuestas los consumidores sitúan los alimentos transgénicos a un nivel de peligrosidad inferior a los aditivos alimentarios o viajar en avión y superior a la cirugía o el viajar en tren.

\section{Legislación sobre los alimentos transgénicos: el caso español}

¿Quién regula la comercialización de estos productos? El ciudadano suele tener la impresión de que existe poco control sobre la comercialización de los alimentos transgénicos. En nuestro país, como en el resto de países miembros de la UE, existe todo un entramado normativo que regula la investigación, liberación al ambiente, patentabilidad, comercialización y etiquetado de estos productos (Tabla 1). De todos ellos los más interesantes son los que hacen referencia a su comercialización y etiquetado.

En la UE, para comercializar por primera vez un alimento transgénico, y siguiendo el Reglamento CE 258/97, es necesario formular una solicitud al Estado miembro en el que se quiere comercializar conteniendo la información técnica necesaria junto con una copia de los estudios de evaluación de riesgo sanitario y ambiental. A continuación se lleva a cabo una evaluación inicial por parte del organismo competente en materia de evaluación en el país de solicitud que puede solicitar evaluaciones complementarias. Una vez se disponga de la evaluación final, el informe se remite a la Comisión que lo distribuirá a todos los países miembros. Los Estados miembros pueden presentar alegaciones u observaciones referentes a la comercialización del alimento. Si se realiza una objeción se adoptará una decisión de autorización que precisará las condiciones de uso del alimento transgénico, su denominación y su descripción, así como los requisitos de etiquetado. 


\section{Daniel Ramón y María Dolores Calvo}

TABLA 1. Normativa jurídica relacionada con la producción, ensayo, comercialización y etiquetado de alimentos transgénicos

- Normativa relativa a la investigación en alimentos transgénicos

Ley 15/1994 de 3 de junio

Real Decreto 951/1997 de 20 de junio

Artículo 349 del Código Penal de 1995

- Normativa relativa a la liberación al ambiente de organismos modificados genéticamente susceptibles de ser utilizados como materia prima de alimentos transgénicos o fuente de obtención de aditivos alimentarios

Ley 15/1994 de 3 de junio

Real Decreto 951/1997 de 20 de junio

Artículos 325, 333 y 349 del Código Penal de 1995

- Normativa relativa a la protección jurídica de los alimentos transgénicos

Directiva 98/44/CE del Parlamento Europeo y del consejo de 6 de julio

- Normativa relativa a la comercialización de los alimentos transgénicos y su etiquetado

Reglamento CE 258/97 de 27 de enero

Reglamento CE 1139/989 de 26 de mayo

Reglamento CE 49/2000 de 11 de enero

Reglamento CE 50/2000 de 11 de enero

De lo descrito se deduce el complicado entramado burocrático para conceder la comercialización de un alimento transgénico en la UE que contrasta con la aparente sencillez de la administración de Estados Unidos. En este país, en 1992 la FDA (Food and Drug Administration) hizo pública una declaración de intenciones en la que afirmaba que no era necesario desarrollar una legislación específica para la comercialización de los alimentos transgénicos, ya que la usada para evaluar la comercialización de los alimentos obtenidos por técnicas genéticas convencionales era suficiente al exigir un análisis detallado de la inocuidad higiénica, sanitaria y medio ambiental del alimento final ${ }^{37}$. Existe por lo tanto una clara contradicción entre el modelo americano que evalúa el producto final sin interesarse por la técnica utilizada para obtenerlo, y el modelo europeo que se fija en ambas cuestiones ${ }^{38}$. En otros países como Australia, Canadá y Japón el sistema es bastante similar al americano. Todavía existen países con una legislación muy laxa o en discusión (Argentina, India) donde se están comercializando 
alimentos transgénicos. Sin duda todas estas diferencias pueden dar lugar a la creación de paraísos de permisividad que, en última instancia, rebajen las medidas encaminadas a asegurar la falta de un riesgo adicional en la comercialización de estos alimentos, algo a todas luces indeseable.

Con respecto al etiquetado, en la UE está contemplado en cuatro reglamentos (Tabla 1). El Reglamento CE 258/97, siguiendo el modelo establecido en su día por la FDA, establece que los alimentos transgénicos deberán etiquetarse sí:

i) No son sustancialmente equivalentes a aquellos de los que proceden, es decir tienen diferente composición nutricional.

ii) Suponen un riesgo para un subsector de la población (por ejemplo exceso de fenilalanina para los enfermos fenilcetonúricos).

iii) Contienen genes de reserva ética o religiosa (genes de un animal en un vegetal para los vegetarianos, genes humanos en cualquier alimento).

iv) Contienen organismos modificados genéticamente vivos.

El segundo Reglamento (1139/98) apareció tan solo un año más tarde del anterior, y regula de una forma particular los alimentos compuestos de soja o maíz transgénico o que contengan aditivos provenientes de estos vegetales transgénicos. Conviene mencionar que éstos fueron los únicos alimentos transgénicos autorizados en la UE previamente a la entrada en vigor del Reglamento 258/97. En este segundo Reglamento se especifica que habrá que etiquetar siempre que se detecte el gen o la proteína transgénica en el alimento final, e incluso indica los requisitos específicos de dicha etiqueta tales como mensaje, tamaño y posición en la etiqueta. En sus considerandos se comenta que la comunidad científica no disponía en el momento de su aprobación de una técnica analítica validada para detectar el gen o la proteína transgénica y que habría que definir los límites de sensibilidad para descartar falsos positivos. Resulta cuanto menos singular el desarrollar una normativa jurídica que se base en una técnica analítica sin disponer de la misma. Además, como recientemente se ha puesto de manifiesto, existe una contradicción jurídica en su formulación, ya que se trata de un reglamento particular, aplicable a dos casos, la soja y el maíz transgénico, cuyo contenido es distinto al previamente descrito para regular la globalidad de los alimentos transgénicos ${ }^{39}$. Sin duda, su publicación ha suscitado muchas reacciones negativas. Cuestiones tales como si cada nuevo alimento transgénico autorizado para su comercialización conllevará el desarrollo de un nuevo reglamento específico 
de etiquetado o si se pueden etiquetar negativamente los alimentos no transgénicos surgen tras su aprobación y recuerdan que su publicación se vio sin duda forzada por presiones políticas. En cualquier caso es un dato más de confusión para el consumidor, cuya lectura del problema es que los científicos son capaces de generar alimentos transgénicos e incapaces de detectar las modificaciones que han introducido. Hace apenas unas semanas han aparecido dos nuevos Reglamentos destinados a definir los límites de detección en el caso de contaminación artificial (Reglamento 49/2000) y el etiquetado de aromas $\mathrm{y}$ aditivos alimentarios obtenidos a partir de organismos modificados genéticamente (Reglamento 50/2000). El espíritu de este último es similar al del Reglamento 1139/98.

\section{Respecto al futuro de los alimentos transgénicos}

Los alimentos transgénicos son una realidad incuestionable. Es evidente que en la actualidad constituyen un problema, pero no es un problema científico ni social, sino económico. Todos los colectivos implicados en el debate tienen sus intereses. Los tienen las compañías multinacionales que los venden y lo quieren hacer cuanto antes, como los tienen algunas de las organizaciones ecologistas con estructura de multinacional que se oponen a su comercialización. Los tienen los científicos que trabajan en organismos públicos y ven peligrar su tema de trabajo, y los tienen los periodistas que han encontrado en este tema un filón de noticias sensacionalistas. $Y$ frente a este conflicto de intereses ¿qué va a hacer el consumidor? Es difícil predecir lo que va a suceder. Nuestra impresión es que todo dependerá de tres cuestiones: la respuesta de la clase política europea frente a la presión social de los grupos que se oponen y la presión económica de las compañías productoras, la posición que adopten los medios de comunicación, y la posible aparición en el mercado de alimentos transgénicos cuya mejora favorezca claramente al consumidor e implique beneficios sanitarios.

En cualquier caso es necesario recordar que la investigación en alimentos transgénicos tiene múltiples repercusiones sociales y jurídicas. Los científicos que trabajan en estos temas no pueden obviarlas, de la misma forma que la sociedad difícilmente podrá prescindir de estos adelantos tecnológicos. En cualquier caso, el intercambio de conocimientos entre científicos sociales y experimentales es, y será, una atrac- 


\section{Debate en torno a la comercialización de los...}

tiva necesidad para llevar a cabo este tipo de investigaciones. Conque algo de eso suceda nos podemos dar por satisfechos.

\section{Bibliografía}

1 Ramón, D. (1999). Los genes que comemos. Editorial Algar, Alzira, Valencia.

2 Roller, S., Goodenough, P.W. (1998). Food enzymes. En: Genetic modification in the food industry (Roller, S. And Harlander, S. eds.). Blackie Academic \& Professional, Chapman \& Hall, London. pp. 101-128.

3 Estruch, J.J., Carozzi, N.B., Desai, N., Dick, N.B., Warren, G.W., Koziel, M.G. (1997). Transgenic plants: an emerging approach to pest control. Nature Biotechnology 15: $137-141$.

4 Schuch, W. (1994). Improving tomato quality through biotechnology. Food Technology 48: 78-83.

5 Arakawa, T., Chong, D.K.X., Langridge, W.H.R. (1998). Efficacy of a food plantbased oral cholera toxin B subunit vaccine. Nature Biotechnology 16: 292-297.

6 Tacket, C.O., Mason, H.S., Losonsky, G., Clements, J.D., Levine, M.M. y Arntzen, C.J. (1998). Immunogenicity in humans of a recombinant bacterial antigen delivered in a transgenic potato. Nature Medicine 5: 607-609.

7 Chen, T.T. (1994). Making transgenic fish. Bio/technology 12: 249.

8 Velander, W.H., Lubon, H., Drohan, W.N. (1997). Producción de fármacos a través de animales transgénicos. Investigación y Ciencia Marzo: 46-51.

9 Jost, B., Vilotte, J.L., Duluc, I., Rodeau, J.L., Freund, J.N. (1999). Production of low-lactose milk by ectopic expression of intestinal lactase in the mouse mammary gland. Nature Biotechnology 17: 160-164.

10 Pascalle, G.G.A., de Ruyter, O.P.K., Meijer, W.C., de Vos, W.M. (1997). Food-grade controlled lysis of Lactococcus lactis for accelerated cheese ripening. Nature Biotechnology 15: 976-980.

11 Querol, A., Ramón, D. (1996). The application of molecular techniques in wine microbiology. Trends in Food Science and Technology 7: 73-78.

12 Hileman, B. (1995). Views differ sharply over benefits, risks of agricultural biotechnology. Chemical Engineering Agosto: 8-17.

13 Riechmann, J. (2000). Cultivos y alimentos transgénicos. Fundación $1^{\circ}$ de Mayo. Madrid.

14 OECD. (1993). Safety evaluation of foods derived by modern biotechnology: concepts and principles. OECD, Paris.

15 OECD. (1996). Food safety evaluation. OECD, Paris.

16 Engel, K., Takeoka, G.R., Teranishi, R. (1995). Genetically modified foods: safety aspects. ACS Symposium Series. Washington.

17 Nordlee, J.A., Taylor, S.L., Townsend, J.A., Thomas, L.A., Bush, R.K. (1996). Identification of a Brazil-nut allergen in transgenic soybeans. New England Journal of Medicine 334: 688-692.

18 Randez-Gil, F., Prieto, J.A., Murcia, A., Sanz, P. (1995). Construction of bakers yeast strains that secrete Aspergillus oryzae alpha-amylase and their use in bread making. Journal of Cereal Science 21: 185-193. 
19 WHO. (1993). Health aspects of marker genes in genetically modified plants. OMS, Geneva.

20 Puig, S., Ramón, D., Pérez-Ortín, J.E. (1998). An optimized method to obtain stable food-safe recombinant wine yeast strains. Journal of Agricultural and Food Chemistry 46: 1689-1693.

21 Ewen, S.S.B., Pustzai, A. (1999). Effcet of diets containing genetically modified potatoes expressing Galanthus nivalis lectin on rat small intestine. The Lancet 354: 1353-1354.

22 Página web de la Royal Society (http://www.royalsoc.ac.uk/st_pol54.htm).

23 Kuiper, A., Noteborn, H.P.J.M., Paijenenburg, A:A.C.M. (1999). Adequacy of methods for testing the safety of genetically modified foods. The Lancet 354: 1315-1316.

24 Nuez, F., Ruiz, J.J. (1997). ¿Constituyen los cultivos transgénicos un riesgo para el hombre o el medio ambiente?. Phytoma 91: 7-16.

25 Joergsen, R.B., Andersen, B. (1994). Spontaneous hybridization between oilseed rape, Brassica napus, and weedy B. campestris (Brasicaceae): a risk of growing genetically modified oilseed rape. American Journal Of Botany 81: 1620-1626.

26 Crawley, M.J., Hails, R.S., Rees, M., Khon, D., Buxton, J. (1993). Ecology of transgenic oilseed rape in natural habitats. Nature 363: 620-623.

27 Losey, J.E., Rayor, L.S., Carter, M.E. (1999). Transgenic pollen harms monarch larvae. Nature 399: 214.

28 Hodgson, J. (1999). Monarch Bt-corn paper questioned. Nature Biotechnology 17: 627 .

29 Knutzon, D.S., Thompson, G.A., Radke, S.E., Johnson, W.B., Knauf, V.C., Kridl, J.C. (1992). Modification of Brassica seed oil by antisense expression of a steroyl-acyl carrier protein desaturase gene. Proceedings of the National Academy of Science USA 89: 2624-2628.

30 Visser, R.G.F., Jacobsen, E. (1993). Towards modifying plants for altered starch content and composition. Trends in Biotechnology 11: 63-68.

31 De la Fuente, J.M., Ramírez-Rodríguez, V., Cabrera-Ponce, J.L., Herrera-Estrella, L. (1997). Aluminium tolerance in transgenic plants by alteration of citrate synthesis. Science 276: 1566-1568.

32 Editorial. (1999). A golden bowl of rice. Nature Biotechnology 17: 831.

33 Zechendorf, B. (1994). What the public thinks about biotechnology. Bio/technology 12: $870-871$.

34 Frewer L.J., Sepherd R. (1998). Consumer perception of modern food biotechnology. En "Genetic modification in the food industry" (Roller, S., and Harlander, S., eds.). Blackie Academic \& Professiona, Londres. pp. 27-46.

35 Hoban T.J. (1996). How japanese consumers view biotechnology. Food Technology 50: 85-88.

36 Hoban, T.J. (1997). Consumer acceptance of biotechnology: an international perspective. Nature Biotechnology 15: 232-234.

37 Kessler, D.A., Taylor, M.R., Maryanski, J.H., Flamm, E.L., Kahl, L.S. (1992).

38 Calvo, M.D., Peris, J., Ramón, D. (1998). Some aspects about food, genes and legislation. Food Science and Technology International 4: 1-4.

39 Ramón, D., Calvo, M.D., Peris, J. (1998). The new regulation for labelling of genetically modified foods: a solution or a problem? Nature Biotechnology 16: 889 . 